\title{
DOS CONCEPTOS DE ESTADO EN EL DEBATE CONSTITUCIONAL ESPAÑOL DE 1931
}

\section{TWO CONCEPTS OF STATE IN THE SPANISH CONSTITUTIONAL DEBATE OF 1931}

\author{
Francisco Javier Bellido \\ Universidad de Málaga
}

\begin{abstract}
SUMARIO: I. INTRODUCCIÓN.- II. EL LENGUAJE POLÍTICO DE LAS CONSTITUYENTES DE 1931.- III. LA COMPOSICIÓN DE LAS CORTES DE 1931.IV. LA DISCUSIÓN SOBRE LA ESTABILIDAD Y CONSOLIDACIÓN DEL ESTADO EN 1931.- V. EL ESTADO: CINCO DEBATES POLÍTICOS.- VI. EL ESTADO Y LOS DERECHOS INDIVIDUALES.- VII. EL MODELO DE ESTADO CONTENIDO EN LA CONSTITUCIÓN.- VIII. CONSIDERACIONES FINALES.
\end{abstract}

Resumen: Este artículo indaga en los argumentos de los constituyentes de 1931 sobre la estructura y el alcance del Estado. Para ello se examinan las intervenciones parlamentarias de los constituyentes entre agosto y diciembre de ese mismo año. Se argumenta que las dos visiones sobre el Estado que rivalizan en las Cortes Constituyentes de la Segunda República se corresponden en gran medida con las alternativas propuestas tanto por el gobierno como por los partidos de la oposición. Ambas representan las disputas ideológicas en torno a, por un lado, un modelo de Estado social de Derecho, defendido por la coalición del primer gobierno; y, por otro lado, una propuesta contraria a ampliar los derechos sociales en el texto constitucional y partidaria de fortalecer los derechos individuales básicos para conformar un Estado liberal de Derecho que reformara así la Constitución de 1876.

Abstract: This article enquires into the arguments held by the constituent members about the structure of the state. For that, MPs turns occurred between August and December 1931 are analysed. It is argued that the two rival views on the state within the Constituent Cortes of the Spanish Second Republic are to a great extent those alternatives held by the government and the opposition. Both portray the ideological disputes about, on the one hand, a model of Social Rule of Law, defended by the first coalition government; and, on the other hand, a proposal opposed to broadening social rights in the constitutional text, whereas in favour of strengthening basic individual rights in the consecution of the Liberal Rule of Law to reform the Constitution of 1876.

Palabras clave: Estado, debate constitucional de 1931, Constitución de 1931, Parlamento, soberanía.

Key Words: state, constitutional debate of 1931, Constitution of 1931, Parliament, sovereignty. 


\section{INTRODUCCIÓN}

Este artículo analiza los significados de la idea de Estado en los debates parlamentarios sobre el proyecto de Constitución española desarrollados entre el 27 de agosto y el 9 de diciembre de 1931. Atiende al uso diferenciado de conceptos políticos comunes como 'gobierno', 'soberanía' o 'constitución' y sus usos retóricos en las intervenciones parlamentarias en relación con el término 'Estado'. Para ello se toman en cuenta dos aspectos previos presentes a lo largo de las sesiones de debate constitucional que dan sentido a las argumentaciones de los distintos representantes politicos en las Cortes de 1931: la fragmentación politica resultante de las elecciones generales de junio de ese año y la polarización de la Cámara en torno a la necesidad o no de reformar las estructuras institucionales del Estado.

Se examina el vocabulario político de los constituyentes para dar cuenta de la orientación partidista de tres fases del debate, las desarrolladas entre septiembre y noviembre de 1931: la relación entre la Constitución, las Cortes y el Estado; el papel del Estado en la economía y la propiedad privada; y la distribución de las competencias entre el Estado y las regiones. Este estudio indaga precisamente en las relaciones semánticas de adjetivos políticos básicos como 'republicano', 'social' o 'integral' en tanto que atribuidos a las diferentes ideas de Estado que defienden los representantes políticos. Su rastreo permite, por tanto, localizar los argumentos politicos empleados por los distintos partidos representados en el Parlamento.

Las concepciones acerca del Estado que rivalizan en las Cortes Constituyentes de 1931 son, a grandes rasgos, dos visiones alternativas sobre la atribución de competencias del Estado que encarnan, de un lado, los partidos de la coalición de gobierno republicano; y de otro, los partidos y parlamentarios no adscritos de la oposición. La primera de ellas, sostenida con distintos matices por el Partido Socialista Obrero Español (PSOE), el Partido Republicano Radical (PRR), el Partido Republicano Radical Socialista (PRRS), el Partido Republicano Progresista (PRP), Acción Republicana (AR) y Organización Republicana Gallega Autónoma (ORGA), representó una visión garantista de las instituciones con respecto a los derechos reconocidos constitucionalmente. En cambio, la segunda de ellas, encabezada por la Minoría Popular Agraria (MPA) y apoyada por diputados independientes o semiindependientes, exigió circunscribir las instituciones de la República dentro del reconocimiento de los derechos individuales, en especial la libertad religiosa, la propiedad privada y las libertades económicas, renunciando parcialmente a consignar nuevos derechos sociales en la Constitución ${ }^{1}$.

1 A continuación se expone una relación de los partidos políticos con representación en las Cortes de 1931: Acción Republicana (AR); Agrupación al Servicio de la República (ASR); Esquerra Republicana de Catalunya (ERC); Extrema Esquerra Republicana (EER); Extrema Izquierda Federal (EIF); Lliga Regionalista de Catalunya (LRC); Minoría Popular Agraria (MPA), coalición integrada por Acción Nacional (AN) y diputados agrarios y monárquicos independientes; Minoría Vasco-Navarra (MVN), coalición integrada por Partido Nacionalista Vasco (PNV), Comunión Tradicionalista (CT) y diputados católicos independientes; Organización Republicana Gallega Autónoma (ORGA); Partido Galeguista (PG); Partido Radical Socialista Revolucionario (PRSR); Partido Republicano de Centro (PRC); Partido Republicano Democrático Federal (PRDF); Partido Republicano Liberal Demócrata (PRLD); Partido Republicano Progresista (PRP); Partido Republicano Radical (PRR); Partido Republicano Radical Socialista (PRRS); Partido Socialista 
La primera parte de la investigación presenta las características distintivas del lenguaje politico de las Cortes de 1931. La segunda parte recoge la composición política del Parlamento tras las elecciones generales celebradas en junio de 1931 y recupera los argumentos básicos de los constituyentes en pro de consolidar el Estado republicano. La tercera parte revisa los argumentos politicos usados en el debate constitucional. La cuarta parte, dividida en tres apartados, selecciona los tres momentos de dicho debate ilustrativos de la controversia en torno a la idea y al modelo de Estado que plasmaba el proyecto de Constitución. La quinta parte resume los principales argumentos sostenidos a lo largo del trabajo contextualizando las visiones alternativas del Gobierno y la oposición acerca del papel que el Estado debía desempeñar en la consolidación del régimen republicano.

\section{EL LENGUAJE POLÍTICO DE LAS CONSTITUYENTES}

Precisar el contexto del debate constitucional de la Segunda República Española implica dar cuenta del modelo parlamentario en que se produce. Las Cortes adoptaron la forma del parlamentarismo racionalizado. Se trató de un modelo promovido por las constituciones europeas de entreguerras, especialmente por la Constitución de Weimar de 1919, que afirmaba la diferencia y distribución de las funciones de los distintos órganos institucionales como dos aspectos prescriptivos de toda constitución.

Por tanto, cabe hablar no sólo de parlamentarismo, sino de constitucionalismo racionalizado también heredero de Weimar y que toma forma en la Constitución de la República Española ${ }^{2}$. Las palabras del diputado agrario Ramón Molina Nieto reflejan que la racionalización del poder a través de la Constitución era una novedad en la politica española de los años treinta: "Podrá, quizá, parecer un poco paradójico esto de la racionalización del Poder refiriéndose a la Constitución, porque si ésta es la expresión del derecho por el cual se rige un pueblo, ¿cómo antes no se entendía así?”3.

Los constituyentes españoles de 1931 unieron las ideas de parlamento y constitución a su racionalización, esto es, a su regulación efectiva a través de normas. En el caso de la Constitución de 1931, incluyendo en ella misma los procedimientos para su reforma y los limites jurídicos de su aplicación. La novedad de este modelo de parlamentarismo consistió en recoger en los textos constitucionales aspectos hasta entonces reconocidos por las leyes ordinarias,

Obrero Español (PSOE); Unió de Rabassaires (UR); Unió Socialista de Catalunya (USC); Unión Monárquica Nacional (UMN).

2 Giacomo Demarchi, "Técnicos parlamentarios y Cortes Constituyentes: Miguel Cuevas y Cuevas en la forja del constitucionalismo de la Segunda República Española”, en Diana Repeto García (coord.) Las Cortes de Cádiz y la historia parlamentaria, Universidad de Cádiz, Cádiz, 2012, p. 630.

${ }^{3}$ DSCCRE, 27.08.1931, $\mathrm{n}^{\circ}$ 28, p. 650. Las siglas DSCCRE designan Diario de Sesiones de las Cortes Constituyentes de la República Española. Todas las referencias incluidas sobre los debates constitucionales y la prensa datan de 1931. En adelante se omite en ellas el año. 
otorgando así un papel preeminente a la Constitución por encima de cualquier otra categoria de normas ${ }^{4}$.

En cualquier caso, conviene señalar que la propia Ley de Defensa de la República de 1931 y el artículo 42 de la Constitución dejaban un amplio margen de maniobra al Gobierno y las Cortes para suspender discrecionalmente derechos individuales plasmados en el texto constitucional. Si bien ambas normas limitaban el alcance real de la Constitución republicana, el artículo 42 del texto constitucional de 1931 era más preciso que el artículo 17 de la Constitución de $1876^{5}$.

En cuanto a su organización parlamentaria, la Constitución reflejaba una forma de organización semipresidencialista llevada a la práctica ya durante el periodo constituyente. Así, la Constitución y el Parlamento aparecen como dos instituciones estrechamente ligadas que limitan el poder del presidente de la República. El Parlamento es la institución que da forma a la Constitución, mientras que ésta regula el papel de la política parlamentaria y la producción legislativa. Dicha politica parlamentaria, siguiendo los modelos constitucionales de entreguerras, se entiende como un instrumento que prescribe y preserva derechos civiles y políticos al mismo tiempo que extiende el reconocimiento de derechos sociales y económicos sólo en la medida en que lo hace a través de una constitución. Esa concepción supuso una ruptura con el modelo constitucional del siglo XIX'.

Este estudio indaga precisamente en las relaciones semánticas de términos políticos clásicos como 'constitución', 'parlamento', 'república' y 'soberania'. Su uso a lo largo de las sesiones de debate constitucional permite localizar los distintos argumentos politicos empleados por los partidos representados en las Cortes Constituyentes. Entre las razones más plausibles que explican la variedad de significados atribuidos al término 'Estado' a lo largo del debate sobresale la ofrecida por Hernández Lafuente: algunos constituyentes consideraban el concepto de Estado como un concepto en desarrollo de escasa precisión terminológica y leve arraigo científico ${ }^{7}$.

Con otras palabras, puede decirse que el de Estado fue un concepto disputado durante el período constituyente por los distintos actores políticos, presentando afinidades semánticas también distintas. El uso de términos y conceptos politicos y sociales comunes a todos los partidos representados en el Parlamento presenta una frecuencia relativa ostensiblemente diferente de acuerdo con la adscripción politica de sus protagonistas. Por ejemplo, la predilección por el lenguaje de los derechos individuales es notable en el caso de los partidos del ala derecha de la Cámara, es también recurrente en diputados del Partido Socialista y Acción Republicana, pero está prácticamente ausente

4 Joaquín Varela Suanzes-Carpegna, Politica y Constitución en España, Centro de Estudios Politicos y Constitucionales, Madrid, 2007, pp. 39-40.

5 Joaquín Varela Suanzes-Carpegna, "La Constitución de 1931 y la organización territorial del Estado", Iura Vasconiae: Revista de Derecho Histórico y Autonómico de Vasconia, 10, 2013 , p. 337.

6 Joaquín Varela Suanzes-Carpegna, Politica y Constitución en España, Centro de Estudios Politicos y Constitucionales, Madrid, 2007, p. 118.

7 Adolfo Hernández Lafuente, La Constitución de 1931 y la autonomía regional. Juan March, Madrid, 1978, p. 14. 
tanto en el Partido Republicano Radical Socialista como en los partidos autonomistas de Cataluña, País Vasco y Galicia.

De acuerdo con la investigación de García Santos sobre el léxico político de la Segunda República, los adjetivos más comúnmente asociados al término Estado durante dicho periodo, entre 1931 y 1939, son los siguientes: 'monárquico', 'antiguo', 'republicano', 'liberal', 'democrático', 'de derecho', 'estéril', 'burgués', 'socialista', 'proletario', 'soviético' y 'de los explotados's. En esta línea pueden distinguirse sustantivos politicos básicos que repiten los representantes de los distintos partidos reunidos en las Cortes de 1931: 'parlamento', 'representación', 'libertad' o 'igualdad' son los más comunes.

Los usos de estos términos con fines retóricos denotan cambios de significado al presentarse junto a nuevos sustantivos y adjetivos que designaban también el banco de pruebas de ideas que fue la política europea de entreguerras $^{9}$. Desde un punto de vista estrictamente ideológico, en el Parlamento de 1931 se dan cita cuatro corrientes políticas: la tradición conservadora; el progresismo burgués identificado bien con el liberalismo social, bien con el republicanismo reformista; el socialismo democrático; y el socialismo radical ${ }^{10}$. Cada una de ellas utiliza un vocabulario específico que se refleja en las jornadas de debate constitucional.

\section{LA COMPOSICIÓN DE LAS CORTES DE 1931}

El resultado de las elecciones generales celebradas el 28 de junio de 1931, favorable a los partidos republicanos de centro e izquierda, posibilitó una coalición de gobierno cuyo gabinete quedó integrado por miembros del Partido Socialista Obrero Español (PSOE), Partido Republicano Radical (PRR), Partido Republicano Radical Socialista (PRRS), Partido Republicano Progresista (PRP), Acción Republicana (AR) y Organización Republicana Gallega Autónoma (ORGA). Como peculiaridad de este primer gabinete de gobierno debe señalarse que cerca de noventa de cada cien diputados electos entonces o bien pertenecían a la coalición gubernamental, o bien eran sus aliados ${ }^{11}$. No obstante, la concurrencia de candidaturas y alianzas también fragmentadas oscurece el desglose de los votos obtenidos por cada uno de los partidos politicos en aquellas elecciones generales ${ }^{12}$.

Con respecto al Reglamento Provisional de las Cortes Constituyentes, su título sexto reguló las normas para la discusión del proyecto de Constitución. El apartado segundo del artículo 22 recogía que en la discusión de totalidad no podría excederse de la presentación de tres turnos en pro y tres en contra. E1

8 Juan Felipe García Santos, Léxico y política de la Segunda República, Universidad de Salamanca, Salamanca, 1980, p. 440.

9 Manuel Álvarez Tardío, "Libertad, poder y democracia: un debate trascendental en la España de la Segunda República", Historia Contemporánea, 43, 2011, p. 660.

10 Clara Álvarez Alonso, "El Estado social de la Segunda República española (1931)", Quaderni fiorentini per la storia del pensiero giuridico moderno, 46 (1), 2017, p. 317.

11 Santos Juliá, La Constitución de 1931, Iustel, Madrid, 2009, p. 38.

12 Javier Tusell, Las constituyentes de 1931. Unas elecciones de transición, Centro de Investigaciones Sociológicas, Madrid, 1982, p. 77. 
apartado sexto de ese mismo artículo recogía que los turnos "serán consumidos por los grupos o fracciones de la Cámara en cuanto tales, para lo cual designarán los representantes que hayan de mantener su criterio politico"13. Este formato se respetó a lo largo de las jornadas de debate constitucional de 1931, si bien es necesario señalar que con frecuencia los turnos de intervención dificilmente podían ser catalogados como intervenciones en pro o en contra. La mezcla de argumentos de apoyo y censura en un mismo turno de intervención reflejó una práctica de debate alejada de procedimientos parlamentarios tradicionales.

Ambos aspectos, una amplia coalición gubernamental y las peculiaridades en la regulación de los turnos de intervención parlamentaria, explican por qué grupos minoritarios en la Cámara como la Minoría Popular Agraria (MPA), la Minoría Vasco-Navarra (MVN) y ocasionalmente diputados independientes o semiindependientes como Ángel Ossorio y Gallardo ${ }^{14}$ y Alfonso García-Valdecasas (ASR) gozaron de protagonismo parlamentario al constituirse como la oposición de facto al gobierno. No obstante, esa circunstancia no impidió que ciertos partidos afines a la coalición de gobierno adoptaran en algunos momentos una disposición contraria al sentido de las reformas emprendidas por éste.

\section{LA DISCUSIÓN SOBRE LA ESTABILIDAD Y CONSOLIDACIÓN DEL ESTADO EN 1931}

El período constituyente de la Segunda República Española se prolongó desde el 27 de agosto de 1931, fecha en la que tiene lugar en las Cortes el discurso de presentación del proyecto constitucional por el diputado del Partido Socialista Obrero Español y líder de la comisión constitucional, Luis Jiménez de Asúa ${ }^{15}$, hasta el 9 de diciembre de aquel mismo año, cuando se aprueba la Constitución. En dicha presentación defendió la fórmula del "Estado integral" como una opción superadora tanto del unitarismo como del federalismo: "Esto es lo que hoy viene haciéndose y esto es lo que ha querido hacer la Comisión, un Estado integral. Después del férreo, del inútil Estado unitarista español, queremos establecer un gran Estado integral en el que son compatibles, junto a la gran España, las regiones [...]"16.

El modelo de Estado integral dibujado en el proyecto constitucional fijaba las leyes prescritas en la Constitución como el limite de las aspiraciones autonomistas que habrian de verse reconocidas en los estatutos de autonomía regionales. Asimismo, establecía el Tribunal de Garantias Constitucionales como el único órgano competente para arbitrar las disputas entre el Estado y las

13 Reglamento Provisional de las Cortes Constituyentes, Gaceta de Madrid, 12.07.1931, p. 341. Todas las fuentes con enlace electrónico que figuran han sido consultadas por última vez en enero de 2019.

14 Ángel Ossorio y Gallardo se presentó como independiente en la denominada candidatura de Apoyo a la República. Destacó como uno de los diputados más activos durante el debate al participar en la gran mayoría de las discusiones sobre los artículos del proyecto de Constitución de 1931.

15 DSCCRE, 27.08.1931, n 28, pp. 642-648.

16 DSCCRE, 27.08.1931, n 28, p. 645. 
regiones ${ }^{17}$. A pesar de estas garantías, Niceto Alcalá-Zamora consideró sustituible el Título II de la Constitución, especialmente los artículos 48, 49 y 50 . En cambio, se mostró partidario de que la Constitución de 1931 especificase cada una de las competencias atribuidas al poder central ${ }^{18}$.

También la prensa republicana acogió con cierto entusiasmo la fórmula integral, considerando como preocupación fundamental de los constituyentes la responsabilidad en la construcción de un nuevo Estado que debía reflejar un orden jurídico propio capaz de responder a las expectativas depositadas en el nuevo régimen republicano. El diputado Rafael Salazar Alonso (PRR) lo anunciaba con las siguientes palabras: "Hemos primero de todo, rodeado nuestro pensamiento de una preocupación: la responsabilidad. Arquitectos de un nuevo Estado, pero alumbradores, sobre todo, de la conciencia jurídica nacional"19.

Durante aquella misma jornada de presentación del proyecto constitucional, y en respuesta al discurso inaugural de Jiménez de Asúa, Claudio SánchezAlbornoz (AR) responde utilizando términos que invitan a la reconciliación de los distintos partidos con representación en las Cortes en el marco del diseño constitucional de un nuevo Estado democrático. Ese nuevo Estado, a su juicio, debía responder a las reivindicaciones de autonomía de algunos territorios, particularmente Cataluña, País Vasco y Galicia, y al mismo tiempo preservar su fortaleza institucional. En cualquier caso, permaneció la desconfianza acerca de las posibilidades reales de ofrecer estabilidad al nuevo régimen democrático republicano: “[...] es necesario, Sres. Diputados, que olvidemos esos rencores viejos, que nos unamos en un camino nuevo, que pensemos en hacer un Estado fuerte, dentro del reconocimiento absoluto de todas esas autonomías; porque ha sido muy fácil, o relativamente fácil, conquistar la libertad, pero es difícil mantenerla" 20 .

De una parte, las palabras de Sánchez-Albornoz suponian un argumento en pro de fortalecer el Estado compatibilizando el reconocimiento de la autonomía regional ya reconocida en el proyecto de Constitución bajo la fórmula del Estado integral. De otra, enfatizaban la debilidad atribuida al Estado republicano frente a las amenazas percibidas en algunos sectores sociales y políticos. Su intervención anticipa lo que será tanto una creencia como un objetivo compartido por la coalición de gobierno que se repetirá a lo largo del debate constitucional de 1931: sólo la consolidación del Estado republicano garantizará el reconocimiento y la extensión de derechos recogidos en el proyecto constitucional.

En un editorial titulado "El momento político: Empieza el debate constitucional”, el diario conservador La Época mostraba su alejamiento de lo que hoy podriamos considerar una visión pluralista de la politica parlamentaria. La creencia de que la República sólo se consolidaría implementando un plan político coordinado y sin fisuras era compartida por un amplio sector de la opinión

17 Juan Enrique Albacete Ezcurra, El Estado integral de la Segunda República española, Nausicaa, Murcia, 2006, p. 204.

18 Niceto Alcalá-Zamora, Los defectos de la Constitución de 1931; Tres años de experiencia constitucional, Civitas, Madrid, 1981 [1934], p. 137.

19 “En la hora solemne de la constituyente", Crisol, 27.08.1931, p. 8.

20 DSCCRE, 27.08.1931, n 28, p. 656. 
pública. Este fragmento lo refleja: "Lo más contrario al concepto de Gobierno, que supone coincidencia fundamental, unidad de acción, concentración de pensamiento en un órgano educativo, es esa dispersión de juicios, esa contradicción de puntos de vista, nada menos que en la organización del Estado y de la nación española"21.

El diputado Eugenio Arauz Pallardó, del Partido Republicano Democrático Federal (PRDF), abogaba por la consolidación del régimen republicano, añadiendo a su intervención tintes federalistas: "[...] la Federación de la República española asegurará la paz interior, que nos es muy necesaria para garantizar y consolidar la República que hemos traído"22.

Esa concepción política que identificó el Estado con el régimen republicano hacía también explícita una consideración muy particular del derecho de excepción. Los partidos de la coalición del gobierno republicano de 1931 coincidian en el temor sobre las posibilidades de consolidación del nuevo régimen debido a la oposición suscitada en algunos sectores sociales ${ }^{23}$. El diario Ahora parafraseaba las declaraciones del lider radical-socialista Marcelino Domingo, quien advertía de los peligros de minar la autoridad del Gobierno republicano: "[...] un quebranto en el Gobierno, cuando apenas se ha comenzado a discutir la ley fundamental del Estado, pudiera acarrear a la República perjuicios de una gravedad insospechada" 24 .

La respuesta de buena parte de la Cámara a ese temor provocó que la garantía de los derechos constitucionales y el funcionamiento institucional permanecieran a expensas de la Ley de Defensa de la República, aprobada el 21 de octubre de 1931. Es decir, la Constitución quedaba en la posición de orden jurídico cuyo ejercicio se circunscribía a lo prescrito por una ley ajena al orden constitucional. La relación entre el Estado y su norma suprema, la Constitución, quedaba así mediada por una ley de excepción. El diputado Ángel Ossorio y Gallardo afirmaba: "[...] no estaba yo prevenido cuando vine a la Cámara de que habría que votar medida tan excepcional como una ley de Defensa de la República que se aparta de la Constitución, que se pone sobre el Código penal"25.

La prensa conservadora respondió negativamente a dicha aprobación, especialmente, contra el hecho de que algunos grupos politicos aprovechasen su posición en la Cámara para plasmar su voluntad: "De esta suerte quedó la República a merced de demandas particulares y a veces del chantaje que sobre ella quisiera ejercer cualquier grupo díscolo, es decir, que se esfumó la supremacía del Estado representante de la nación contra todo partidismo"26.

A lo largo de las distintas intervenciones parlamentarias en el debate constitucional, la inseguridad sobre las posibilidades de estabilidad y

21 “Empieza el debate constitucional”, La Época, 27.08.1931, p. 1.

22 DSCCRE, 16.09.1931, nº 39, p. 956.

23 Abraham Barrero Ortega, "La defensa extraordinaria de la República", en Luis Gordillo Pérez, Sebastián Martín y Víctor Vázquez Alonso (dirs.) Constitución de 1931: estudios jurídicos sobre el momento republicano español, Marcial Pons, Madrid 2017, p. 235.

24 “Se conjura la crisis", Ahora, 27.09.1931, p. 4.

25 DSCCRE, 8.12.1931, N 87, p. 2888.

26 "La República a merced del chantaje de los díscolos", ABC, 8.12.1931, p. 20. 
consolidación del régimen republicano mostró claras filiaciones partidistas. E1 uso de argumentos de legitimidad sobre la necesidad de extender las facultades del Estado fue contestado en la Cámara con habilidad desigual por las fuerzas de la oposición. Estos grupos, fundamentalmente la Minoría Popular Agraria y la Minoría Vasco-Navarra, apelaron con frecuencia a lo que consideraban excesos cometidos por el Estado republicano con respecto al régimen de propiedad, la libertad religiosa y la política fiscal.

A través del lenguaje de las libertades individuales, José María Gil-Robles (MPA) contextualizaba cuál era, a juicio de su formación, el espacio de acción de los poderes públicos del Estado:

"Si la Constitución es ley fundamental de la Nación, donde se regula el juego de todos los Poderes del Estado y se definen los derechos del individuo frente al Poder público, dicho se está [sic] que la Constitución, si ha de responder a su esencia, ha de realizar la libertad y ha de salvaguardar la justicia y ha de poner en armonía todas las exigencias del progreso humano con la libertad individual $[\ldots] " 27$.

Esta intervención de Gil-Robles puede explicarse parcialmente como el resultado de tres factores que determinaron las concepciones enfrentadas en los debates políticos sobre el Estado. El primero, mencionado anteriormente, tuvo que ver con la fragmentación parlamentaria resultante de los comicios celebrados el 28 de junio de 1931. El segundo, en cierta medida consecuencia del primero, obedeció a las alianzas coyunturales y la búsqueda constante de apoyos por parte de la coalición de gobierno en torno a las fuerzas de centro e izquierda. El tercer factor tuvo que ver con las diferencias ideológicas. Estos dos últimos factores provocaron una clara división entre los partidos politicos partidarios de ampliar las facultades del Estado y sus detractores ${ }^{28}$.

Las decisiones de los gabinetes de gobierno de Niceto Alcalá-Zamora (PRP), hasta su dimisión en octubre de 1931, y de Manuel Azaña (AR) después, demuestran que los artículos constitucionales más conflictivos fueron aprobados con el apoyo del Partido Republicano Radical y del Partido Republicano Radical Socialista. Así ocurrió en la jornada del 13 de octubre de 1931 cuando los diputados de estos dos partidos votaron a favor del artículo 26 de la Constitución (artículo 24 en el proyecto constitucional) ${ }^{29}$. Ambas formaciones se mostraron especialmente combativas en la defensa del artículo 27 (artículo 25 en el proyecto constitucional), junto al 26, uno de los artículos referidos a la denominada cuestión religiosa ${ }^{30}$.

Esa circunstancia determinó que dos minorías, la Minoría Popular Agraria y la Minoría Vasco-Navarra, junto con algunos diputados independientes, se

27 DSCCRE, 15.09.1931, n 38, p. 921.

28 Pablo Oñate Rubalcaba, "Elecciones, partidos y sistemas de partidos en la España democrática", en Francisco Murillo y José Luis García de la Serrana. Transformaciones politicas y sociales en la España democrática, Tirant lo Blanch, Valencia, 2006, p. 403.

29 DSCCRE, 13.10.1931, n 55, 1719-1720.

30 Durante la sesión celebrada el 15 de octubre, $\mathrm{n}^{\circ} 57$, intervienen por parte de estos grupos Clara Campoamor (PRR) (DSCCRE: 1735), Eduardo Ortega y Gasset (PRRS) (DSCCRE: 1740) y Ricardo Samper (PRR) (DSCCRE: 1755). 
convirtieran en la oposición parlamentaria a la coalición del gobierno republicano. Algo que puede comprobarse cuando se analiza la frecuencia de las intervenciones parlamentarias de estos partidos a lo largo del mes de octubre de 1931, puesto que se contabilizan un total de 33 intervenciones a cargo de estos grupos en dicho periodo del debate constitucional.

Esa información permite rastrear el papel desempeñado por diputados de distintas formaciones. De ese modo, puede analizarse la labor parlamentaria de grupos políticos cuyo escaso número de diputados no fue un obstáculo para que gozaran de protagonismo a lo largo de las sesiones celebradas en las Cortes. De ello da buena muestra el hecho de que en los debates politicos acerca del Estado el diputado Antonio Royo Villanova (MPA) fuese uno de los parlamentarios más activos. Su minoria y otros diputados afines participaron en el debate constitucional de forma recurrente ${ }^{31}$.

\section{EL ESTADO: CINCO DEBATES POLÍticos}

Tal y como aparecen las menciones explícitas sobre el Estado a lo largo del debate constitucional de 1931, es posible afirmar que son cinco los debates en que el término aparece propiamente como un concepto político. Estos debates giran en torno a la distribución de las competencias entre el Estado y las regiones (22-25 de septiembre); el papel del Estado en la economía y la propiedad privada (6-7 de octubre); las relaciones entre el Estado y la Iglesia (8-13 de octubre); las competencias del Estado en materia educativa (21 de octubre); y la relación entre la Constitución, el Parlamento y el Estado (del 29 de octubre al 4 de noviembre) ${ }^{32}$.

Los títulos V (Presidencia de la República), VI (Gobierno) y IX (Garantías y reforma de la Constitución) incluidos en la Constitución de 1931 fueron debatidos en la Cámara siguiendo el orden numérico de los artículos ${ }^{33}$. Sin embargo, el examen de las distintas jornadas de debate constitucional hace visible una discusión recurrente sobre la institución presidencial, el papel del Parlamento en el Estado republicano y la vigencia de la Constitución finalmente aprobada.

Estas cuestiones de debate, aunque de forma dispersa, permanecen a su vez conectadas con la discusión del proyecto de Constitución artículo por artículo a lo largo de las sesiones. Por esa razón es dificil hacer corresponder univocamente las discusiones politicas acerca del Estado con el debate de artículos particulares del proyecto. Sin embargo, sí pueden distinguirse distintas fases del debate en las Cortes en las que los constituyentes mencionan el Estado de manera explícita. Esta circunstancia permite delimitar los sentidos concretos que el término 'Estado' adquiere en relación con cada uno de los temas de debate político seleccionados.

31 Como muestra, el 2 de octubre, $\mathrm{n}^{\circ}$ 49, intervienen en el Parlamento Antonio Royo Villanova (MPA) (DSCCRE: 1397), José María Gil-Robles (MPA), en tres ocasiones (DSCCRE: 1413,1417 y 1423) y Jesús María de Leizaola (MVN) (DSCCRE: 1418). El 6 de octubre intervienen Rafael Aizpún (MVN) y Gil-Robles (DSCCRE: 1440), Pedro Martín y Martín (MPA) (DSCCRE: 1464), y Tomás Alonso de Armiño (independiente) en dos ocasiones (DSCCRE: 1466).

32 Santos Juliá, op. cit., pp. 54-68.

33 Constitución Española de 1931. 
A continuación, se analizan tres de estos debates en los que se presentan interpretaciones rivales sobre la idea de Estado, a saber, su relación con la Constitución y las Cortes; su papel en la economía y la propiedad privada; y la distribución de sus competencias con las regiones. Las relaciones entre el Estado y la Iglesia y el papel del Estado en materia educativa, aunque fundamentales para una comprensión cabal del peso institucional del Estado republicano, presentan diferencias llamativas con respecto a los tres debates restantes. En dichas sesiones las referencias a presupuestos jurídicos o intelectuales sobre la idea de Estado son escasas. De ahí que esos dos debates apenas resulten relevantes para el análisis.

En ese sentido, debe destacarse que la mayoria de los constituyentes que demuestran un conocimiento solvente de las instituciones del Estado proceden del ámbito del Derecho: Luis Jiménez de Asúa y Jerónimo Bugeda (PSOE); José Maria Gil-Robles y Antonio Royo Villanova (MPA); Ricardo Samper (PRR); Francisco López de Goicoechea (PRRS); Melquíades Álvarez (PRLD) y Alfonso García-Valdecasas (ASR) ${ }^{34}$.

Su actividad simultánea como políticos y juristas se trasladó al debate parlamentario. La habilidad de los constituyentes para anticipar conflictos en el seno de la norma fundamental propició el concurso de justificaciones y alertas sobre cada aspecto del proyecto de Constitución. Ello significó en muchos casos un ejercicio de claridad argumental que permite identificar con un alto grado de certeza la influencia jurídica e ideológica de los constituyentes. A continuación se revisan esas intervenciones, junto a las de otros constituyentes, para contrastar los distintos significados atribuidos al Estado.

\section{EL ESTADO Y LOS DERECHOS INDIVIDUALES}

Siguiendo el orden cronológico de los debates seleccionados, Félix Gordón Ordás (PRRS) fue el primero de los constituyentes que hizo referencia explícita al Estado. Intervino utilizando términos que reflejaban la influencia de la escuela hegeliana de filosofía y esbozó en las Cortes una compresión del Estado que implicaba una renuncia de los individuos en aras de la construcción de un Estado fuerte: "[...] en el Estado fuerte actual es el propio individuo quien al analizarse por dentro y comprender que para la relación de su 'yo' con el 'yo' ajeno es necesaria una conexión pierde parte de su libertad, pierde parte de su individualidad y proclama la necesidad de crear un Estado fuerte"35.

La oposición entre Estado e individuo, por lo demás, también fue un lugar común entre los partidos de centro y derecha. El Partido Republicano Radical, aún en la coalición de Gobierno, insistió en el potencial carácter invasivo del Estado en el terreno de las libertades individuales. Así, Ricardo Samper (PRR) declaraba:

34 Jiménez de Asúa fue profesor de Derecho Penal; Bugeda perteneció al cuerpo de Abogados del Estado; Gil-Robles se desempeñó como catedrático de Derecho Político; Royo Villanova, como catedrático de Derecho Administrativo; Samper ejerció como abogado; López de Goicoechea perteneció a la Real Academia de Jurisprudencia y Legislación; Álvarez fue catedrático de Derecho Romano; y García-Valdecasas, catedrático de Derecho Civil.

35 DSCCRE, 1.09.1931, nº 30, p. 706. 
"En [sic] fin de cuentas, el Estado no es más que una gerencia de los servicios públicos, y que el derecho y la libertad del individuo están por encima del Estado y no pueden restringirse más que en aquella medida que exigen la convivencia y la coordinación con el derecho y la libertad de los demás ciudadanos" 36 .

La defensa del 'Estado fuerte' puede rastrearse en las intervenciones de diputados adscritos a distintas formaciones. Las declaraciones de Luis Araquistáin (PSOE) a la prensa bajo ese mismo rótulo, 'Estado fuerte', son ilustrativas de la visión de buena parte de los diputados socialistas acerca del papel del Estado republicano: "El agotamiento del liberalismo clásico, que ha ido a acabar en la anarquía económica que hoy aqueja a la humanidad entera, ha creado de nuevo la urgencia de un Estado fuerte que controle y reorganice una sociedad amenazada en sus bases por el predominio ilimitado de todos los instintos de presa"37.

En un sentido partidario de la concesión de amplias facultades al Estado se manifestó Fernando Valera (AR). A su juicio, el Estado que la Constitución iba a reflejar no se oponía a las libertades individuales, sino que los poderes del Estado se erigían en pieza clave para su reconocimiento eficaz. Aquí aparece una idea básica sobre la legitimidad del Estado: “[...] no le ponemos más que un límite a la fortaleza del Estado, que es la legitimidad de su origen, los derechos del hombre y de la colectividad" 38 .

No debe sorprender que la colectividad aparezca como sujeto político. Esta mención explícita se repite en palabras del propio Gordón Ordás (PRRS) en la jornada del 1 de septiembre, y en palabras de José Ortega y Gasset (ASR): "[...] la voluntad de una colectividad que lleva en brazos los cambiantes destinos políticos de un pueblo a través de los siglos"39. La conexión del término 'colectividad' con la defensa de los derechos que algunos diputados consideraban propios de los grupos sociales estaba lejos de ser clara. El sentido con el que Ortega y Gasset invoca la colectividad en términos de voluntad guarda una conexión más estrecha con su idea de que existe una voluntad histórica española y no necesariamente con el concepto de soberania nacional.

Melquíades Álvarez (PRLD), líder del minoritario partido centrista antes denominado Partido Reformista, se interesó, en cambio, por el carácter eficaz de la Constitución en su relación jurídica con el Estado. Para ello, destacó el Estado nacional como la única forma politica que debía recoger la Constitución. En su intervención conmina a construir una constitución que antes que impecable desde el punto de vista de su redacción y el amplio reconocimiento de los derechos políticos debería reflejar "[...] el estatuto jurídico y político del país, con todas sus imperfecciones, con todos sus errores, con su fanatismo" 40.

\footnotetext{
36 DSCCRE, 11.09.1931, n 37, p. 871.

37 "Estado fuerte", El Sol, 10.11.1931, p. 1.

38 DSCCRE, 15.09.1931, n 38, pp. 925-926.

39 DSCCRE, 25.09.1931, no 45, p. 1256.

40 DSCCRE, 9.09.1931, n 35, p. 816.
} 
En el terreno del debate sobre los derechos que la futura constitución debía reconocer y cuál debía ser el papel de las instituciones del Estado, Luis Araquistáin (PSOE) anticipaba que el reconocimiento constitucional de los derechos individuales significaba también un cambio con respecto al papel normativo del Estado y su concepción como organización política garante de servicios públicos:

"Estamos pasando del Estado individualista subjetivo, el de los derechos absolutos, a un Estado de normas, a un Estado normativo que no será un simple instrumento de fuerza, sino un organizador de servicios y un guardián de las normas de cooperación y justicia que se derivan de estos servicios" 41 .

Una concepción similar en torno al futuro papel del Estado, aunque otorgándole explícitamente un papel activo en oposición a las consideradas como insuficiencias de la iniciativa individual, fue sostenida en el debate por Antonio Rodriguez Pérez (ORGA):

"[...] el Estado tiene una misión permanente y una misión accidental o histórica; la misión permanente es la de velar por la integridad y coordinación de los derechos, y la misión histórica, accidental, es la de suplir las insuficiencias o inexistencias de iniciativas de los individuos que conduzcan al mejor logro del fin social" 42 .

Esa visión de la función social de todas las acciones en el marco del Estado era además ampliamente compartida por los constituyentes de izquierdas. Se trataba de un presupuesto básico desde el que llevar a cabo la amplia acción reformista que el Estado debía emprender partiendo de la Constitución. La doble función atribuida por el reformismo al nuevo Estado constitucional republicano consistía, por un lado, en la ampliación de los derechos reconocidos constitucionalmente y, por otro, en reconocer la función social, lo que chocaba, a juicio del reformismo de centro-derecha, con el reconocimiento eficaz de la iniciativa económica privada y la garantía de los derechos y libertades individuales.

No obstante, en ambos sentidos el Estado se constituía en una organización jurídico-política, y por tanto realizable, con potencialidades en el progreso económico de la sociedad. La idea de racionalización del poder político, es decir, de sometimiento de los poderes públicos al Derecho, se hace patente a través de una concepción de las normas constitucionales en tanto que "normas directamente aplicables" (Escudero, 2017: 104). Se trata de una idea reflejada en los discursos de los diputados que toman en cuenta los fracasos anteriores en la historia política de España, "sobre todo el fracaso del Estado"43.

Con esta idea de racionalización del poder politico se significaba una acción reformista de carácter obligado para las fuerzas de izquierda moderada que, al mismo tiempo, tomaba el cariz de una obligación ideológica. En última instancia, implicaba una forma de entender los complejos engranajes de las distintas

${ }^{41}$ DSCCRE, 16.09.1931, n ${ }^{\circ}$ 39, p. 943.

42 DSCCRE, 22.09.1931, nº 42, p. 1038.

43 Marie-Angèle Orobon, "La nación republicana entre herencia y ruptura. Una aproximación a la definición de España en el debate constitucional de 1931", Historia Constitucional, 10, 2009, p. 214. 
estructuras del Estado inspirada en la Constitución de Weimar de 1919 y en la Constitución Austriaca de 1920. Frente a estas constituciones la Constitución Española de 1931 reconocía, en el caso de la justicia, no sólo su independencia administrativa, sino también su acceso gratuito facilitado por el Estado para quienes no contasen con recursos económicos suficientes: "La República asegurará a los litigantes económicamente necesitados la gratuidad de la Justicia"44.

No es de extrañar, por tanto, que la discusión sobre el papel de la administración del Estado surgiera con fuerza en aquella misma jornada de debate del 24 de septiembre de 1931. Antonio Royo Villanova (MPA), el constituyente más activo de la oposición al gobierno, intervenía mostrando su rechazo a la cesión de competencias administrativas a las regiones por cuanto las consideraba una amenaza para la propia soberanía del Estado. No obstante, admitía como necesarias ciertas concesiones de autonomía administrativa a cada una de las regiones españolas:

"[...] la autonomía administrativa es un principio aceptable acerca del cual se puede discutir; pero la autonomía política con soberanía, mermando la soberanía política del Estado, esto ya es un concepto muy grave, y de más gravedad para unas Cortes Constituyentes"45.

La presión de Esquerra Republicana de Catalunya sobre socialistas y radicales convirtió al partido catalanista fundado en 1931 en una fuerza clave. La aprobación de los artículos constitucionales por una mayoría de votos favorables resultaba difícil como consecuencia de desacuerdos entre el Partido Socialista Obrero Español y el Partido Republicano Radical. La Lliga Regionalista, el partido catalanista con mayor tradición politica, resultó prácticamente irrelevante para la aprobación de los distintos artículos de la Constitución. En cambio, el apoyo parlamentario de los 29 diputados adscritos a Esquerra Republicana sí jugó un papel determinante. Asimismo, las disputas entre socialistas y republicanos radicales dieron lugar a que los segundos respaldasen buena parte de las pretensiones federalistas y se negasen a reconocer el Estado integral como una fórmula válida para las distintas regiones de España ${ }^{46}$.

Sobre el debate regional tuvieron cabida en las Cortes cinco posturas diferenciadas. La primera de ellas estuvo representada por los grupos monárquicos conservadores y afines al ejército, que consideraban cualquier fórmula autonomista o federalista una amenaza para la unidad territorial de España. La segunda alternativa fue encarnada por los conservadores seguidores de Emilio Castelar y Gumersindo de Azcárate, partidarios de cierta descentralización como medida preventiva frente a las demandas de los partidos nacionalistas. La tercera postura consistió en la vía federalista heredera de Pi i Margall que apoyaban algunos diputados a título personal: Hilario Ayuso, José Franchy y Roca o Gregorio Arranz, entre otros. La cuarta, adoptada de forma compleja por distintas corrientes, agrupaba fórmulas autonomistas con las reivindicaciones de Esquerra Republicana de Catalunya y otros grupos de corte

44 Constitución Española 1931, artículo 94.

45 DSCCRE, 24.09.1931, nº 44, p. 1131.

46 Santiago Varela Díaz, 1976, El problema regional en la II República Española, Unión Editorial, Madrid, pp. 46-47. 
nacionalista. La quinta, en cambio, recuperaba el modelo confederal y fuerista, caso del Partido Nacionalista Vasco y la Comunión Tradicionalista agrupadas en la Minoria Vasco-Navarra ${ }^{47}$.

Representando la primera de las vías comentadas, el discurso político de la Minoria Popular Agraria de Royo Villanova se caracterizó (también en gran medida el de su correligionario y líder del partido, José María Gil-Robles) por el recurso al argumento de la pérdida de soberanía que suponían algunas de las acciones emprendidas por el gobierno, fundamentalmente, la autonomía regional y la separación de la Iglesia y el Estado. La soberanía, en el uso político de la Minoría Popular Agraria, no remitía específicamente a la soberanía popular o nacional, sino a los espacios de autonomía de los distintos poderes del Estado, en especial del ejecutivo, así como a las instituciones de la sociedad civil y la Iglesia Católica. Especialmente clarificador de su postura política acerca del Estado y la soberanía es su discurso del 24 de septiembre de 1931, del que anteriormente se citaba un pequeño fragmento ${ }^{48}$.

En la jornada siguiente, el diputado Samper exponía con claridad cuál era la postura del gobierno sobre la cesión de facultades administrativas a las regiones y sobre el alcance de los futuros estatutos de autonomía regionales, fundamentalmente el catalán. La distribución de competencias (en aquel momento el término más recurrente fue el de "facultades") supuso una piedra de toque para el gobierno republicano: "Esta capacidad jurídica [la legislación] sólo puede medirla el Estado; es decir, el Parlamento, que es el llamado a aprobar el Estatuto y a graduar el máximum o mínimum de jurisdicciones que quiera conceder a la región autónoma"49.

La réplica de Royo Villanova demostraba las reticencias de la oposición para transigir ante un modelo de Estado que la Minoría Popular Agraria consideraba pernicioso en el largo plazo para el propio Estado, circunstancialmente identificado con el Parlamento como órgano de soberania: “[...] a los defensores del Estado no nos puede satisfacer la tasa de atribuciones [entre las regiones autónomas y el Estado], porque eso es mermar la soberanía del Estado"50.

En esa línea Cándido Casanueva, también diputado agrario, refería la obligación del Estado en disponer de todos los medios para el mantenimiento del orden público, una facultad que consideraba irremisiblemente ligada al Estado y sólo al Estado y que quedó expresada nuevamente en referencia a la soberanía: "Entiendo yo que la primera obligación del Estado es mantener el orden en toda la Nación de tal manera, que el Estado, que abandona la conservación del orden en manos de otras entidades [las regiones], no es Estado completamente soberano" 51 .

Las declaraciones de Alcalá-Zamora (PRP) al diario La Voz cinco días más tarde ponían de manifiesto que el Estado republicano era entendido como tal en

\footnotetext{
47 Juan Enrique Albacete Ezcurra, op. cit., p. 27.

48 Las páginas 1131 y 1132 del Diario de Sesiones, que se corresponden con la intervención de Royo Villanova en esa fecha, contienen 53 veces el término 'soberania'.

49 DSCCRE, 25.9.1931, n 45, p. 1194.

50 DSCCRE, op. cit., pp. 1197-98.

${ }^{51}$ DSCCRE, op. cit., p. 1222.
} 
relación con la Constitución. Asimismo, preservar la libertad y la paz brindadas por la norma fundamental exigía, a su juicio, que todas las fuerzas políticas implicadas en el Parlamento mantuviesen la calma en los debates más controvertidos, como en el caso de la denominada cuestión religiosa. AlcaláZamora entendía que el Estado debía actuar como garante de los derechos individuales como la independencia religiosa sin incurrir en excesos que los limitasen: "Depende [...] esa facilidad [para discutir la cuestión religiosa] de que todos tengamos la serenidad necesaria para comprender que a España le conviene una Constitución de paz y libertad, con la obligada independencia y salvaguardia del Estado"52.

Ligar el concepto de Estado al de soberanía, y ambos al de Parlamento, sin distinciones, provocó que se pronunciase en contra uno de los miembros más destacados de la Comisión Jurídica Asesora, Alfonso García-Valdecasas (ASR). En tanto que jurista y miembro de la comisión encargada de redactar el anteproyecto de Constitución finalmente desechado por las Cortes, juzgaba una confusión conceptual profunda de los constituyentes su concepto jurídico y funcional del Estado: "El Estado, señores (quiero recalcar esto para que no se hagan objeciones impropias), no se confunde con ninguno de sus órganos; el Estado no es el Gobierno: el Estado no es tampoco el Parlamento; todo esto son aparatos más o menos perfeccionables al servicio del Estado"53.

Es posible afirmar que la posición de García-Valdecasas se identificaba sin ambages con el constitucionalismo moderno de inspiración centroeuropea y francesa. En su intervención define no sólo la localización del Estado en el entramado jurídico de las instituciones políticas, sino que señala también la Constitución como el instrumento rector de la política legislativa estatal. No obstante, no emplea el lenguaje de las instituciones; en su lugar, opta por el término "aparatos" para referir los distintos órganos que dan forma al Estado constitucional.

\section{EL MODELO DE ESTADO CONTENIDO EN LA CONSTITUCIÓN}

La preeminencia de la Constitución marca entonces el espacio de acción del Estado abriendo o vetando futuros cauces de acción legislativa, una concepción que hundía sus raíces en la reciente experiencia constituyente europea de entreguerras. Sus dos principales características consistieron, primero, en una nueva forma de entender las relaciones entre el Estado y la sociedad, mediadas ahora por una Constitución que las garantizaba; y segundo, en la ruptura parcial con el Estado liberal del siglo XIX (Varela Suanzes-Carpegna, 2007: 583) ${ }^{54}$.

Dentro de ese nuevo modelo de Estado constitucional europeo de entreguerras, el reconocimiento de los derechos sociales coexiste también con la garantía de los derechos estrictamente individuales. Sin embargo, la visión activa del Estado defendida en las Cortes por el socialismo moderado recogía la expropiación forzosa como una función del propio Estado. Así fue reconocida en

52 “Una declaración del Sr. Alcalá Zamora para La Voz", La Voz, 30.09.1931, p. 1.

53 DSCCRE, 1.10.1931, n 48, p. 1364.

54 Joaquín Varela Suanzes-Carpegna, Politica y Constitución en España, Centro de Estudios Politicos y Constitucionales, Madrid, 2007, p. 583. 
el apartado 12 del artículo 15 de la Constitución de 1931: "Derecho de expropiación, salvo siempre la facultad del Estado para ejecutar por sí las obras peculiares".

El diputado socialista Jerónimo Bugeda lo justificaba en términos de "intervencionismo activo", contando con la oposición de Juan Castrillo (PRP), Alfonso Ossorio y Gallardo (diputado independiente) y José María Gil-Robles (MPA): "[...] es menester que el Estado, por un principio de intervencionismo activo, hasta que llegue la hora de nacionalizar, que ha de ser una obra inmediata, disponga en un momento dado de todos los resortes de la economía nacional $[\ldots] " 55$.

Ante los excesos de su compañero de partido, el propio presidente de la Cámara, Julián Besteiro (PSOE), se vio obligado a intervenir para corregir el enfado causado entre buena parte de los parlamentarios: "No pensemos ni tengamos la obsesión del socialismo de Estado, que, con todos sus medios de coacción, fuerce a los ciudadanos a adoptar una forma determinada de propiedad: ese socialismo no es el nuestro"56.

Que el Estado reformista republicano se convirtiese en un Estado intervencionista en todos los ámbitos de la vida pública constituía para sus detractores una amenaza potencial que el vocabulario beligerante del marxismo ortodoxo introdujo entre algunos parlamentarios. Ese discurso proliferó en algunos momentos del debate, también en torno a la denominada cuestión religiosa, contribuyendo al distanciamiento de los sectores de la derecha moderada de la Cámara con respecto al proyecto constitucional.

Esa visión partidaria de delimitar el poder de acción del Estado se trasladó a las Cortes en una forma que recuperaba en parte la voz de la tradición constitucional conservadora regalista del siglo XIX. El diputado de Acción Nacional Santiago Guallar otorgaba a la soberanía de la nación un sentido literal. La nación aparece como sujeto político en reemplazo de la voluntad popular. Se trataba de un intento de justificar la acción politica constitucional en base a una supuesta realidad social de la nación, una interpretación que desdeña cualquier intervención de carácter planificador o idealista en el sentido de adecuar la Constitución española a los ideales de un determinado grupo social por parte del Estado: "[...] el Estado no puede moldear conforme a planes ideales a la Nación, sino que la Nación es la que tiene Derecho a que se la respete en su constitución; no es el Estado el arquitecto de la Nación, es ésta la que tiene el derecho a formar el Estado y la Constitución conforme a su imagen y semejanza"57.

Durante algunas jornadas, el debate sobre el Estado desaparece de las sesiones parlamentarias hasta la jornada del 30 de octubre de 1931. En esa fecha José Ortega y Gasset (ASR) pronuncia un discurso reflexivo en torno al dictamen de la Comisión de la jornada anterior que él intuye como el principal escollo para la configuración de un Estado parlamentario en España homologable con el resto de los países europeos: "En el dictamen de la Constitución va dibujada cierta figura de Estado, que consiste en dar al Poder Ejecutivo y al

\footnotetext{
55 DSCCRE, 6.10.1931, n 50, p. 1435.

56 DSCCRE, op. cit., no 50 , p. 1444.

57 DSCCRE, 13.10.1931, no 55, p. 1656.
} 
parlamentario la plenitud de sus atributos, pero cuidando de fortalecer ambos y de dotarlos de suficiente independencia. Frente a esta figura de Estado, cabe siempre, ¡no faltaba más!, la tradicional, la que el último siglo nos presenta, en la cual el Poder ejecutivo queda supeditado al parlamentario [...]"58.

Ortega da cuenta de la tensión que de hecho existió entre la voluntad del gobierno por construir una democracia parlamentaria efectiva y, al mismo tiempo, capaz de garantizar la fortaleza del poder ejecutivo, la propia fortaleza del gobierno. Por un lado, su fórmula distingue el poder ejecutivo del Estado, evitando así una confusión común consistente en identificar a ambos. Por otro lado, advierte de la necesidad de limitar el poder ejecutivo mediante la labor fiscalizadora del parlamento. El diputado Juan Castrillo (PRP) deshace esa confusión conceptual cuando afirma:

"Las leyes, para que sea verdad la independencia del Poder judicial, tienen que hacer algo más que proclamarla, y es garantizar todo aquel orden de condiciones necesario para que la independencia sea un hecho; es decir, desconectar los tribunales de Justicia del Poder del Estado, desconectarlos del Poder ejecutivo"59.

Esas distintas formas de entender el Estado republicano se reflejan también en la prensa. Los sectores más reacios a aceptar el régimen republicano dejan traslucir una visión que hace corresponder el Estado con la que consideran una voluntad de exclusión ejercida por los sectores reformistas representados en las Cortes: "Aspiran a la revisión constitucional, unos por fervor religioso; otros, relegando sus ideas religiosas al fuero de la conciencia, por sencillo sentimiento liberal. A impulsos de aquél, se va dibujando en la política de España la silueta de un partido católico -consecuencia inevitable de la política persecutoria practicada e inscrita en el texto constitucional-"60.

Más adelante en el mismo artículo se explicitan las razones del rechazo al proyecto constitucional. Con respecto a la enseñanza se afirma que la educación no debe quedar en manos del Estado, que para los sectores católicos no se trata sino de una abstracción que consideran suplantadora de las decisiones de los padres con respecto a la educación que deben recibir los hijos: 'La 'función' -en el significado de cometido- del Estado, esto es: de los demás individuos componentes del agregado social, no es suplantar a los padres, tiranía insufrible e irrealizable, crimen contra la Naturaleza, sino auxiliarles, y cuando aquellos faltan, sustituirles"61.

Más beligerante aún se mostró Acción Española: no sólo rechazó el proyecto constitucional y el propio Estado republicano, sino también el proceso de redacción y enmiendas parlamentarias llevado a cabo en las Cortes Constituyentes entre agosto y diciembre de 1931: "Se atienden y previenen los últimos detalles para que la máquina del Estado pueda correr por su propia

\footnotetext{
58 DSCCRE, 30.10.1931, nº 66, p. 2064.

59 DSCCRE, 17.11.1931, no 75, p. 2380.

60 "La revisión constitucional”, La Época, 10.12.1931, p. 1.

61 "La revisión constitucional”, op. cit., p. 1.
} 
presión a lo largo de los rieles que le han ido tendiendo en varios meses de labor parlamentaria"62.

Como se ha visto en el caso de la Minoría Popular Agraria, el concepto de Estado aparecía ligado al de soberanía. Por soberanía Royo Villanova entiende la autonomía de las instituciones civiles, incluida la propiedad, con respecto al Estado. Los partidos de la derecha y el centro reformistas, como el Partido Republicano Progresista de Niceto Alcalá Zamora, el Partido Republicano Liberal Demócrata de Melquíades Álvarez y la Agrupación al Servicio de la República, se inclinaban por un modelo de Estado reformista compatible con la iniciativa privada y el reconocimiento gradual de derechos sociales. Por su parte, los diputados de izquierda moderada -fundamentalmente diputados del Partido Socialista y de Acción Republicana- confiaban en la construcción de un Estado garantista capaz de extender los derechos politicos y desempeñar un papel activo en la economía.

\section{CONSIDERACIONES FINALES}

El modelo reflejado en la Constitución de 1931 permitió construir un Estado democrático social que complementó al Estado de Derecho tal como fue materializado en las constituciones europeas de entreguerras. Supuso la reformulación del concepto regalista de Estado presente en buena parte del siglo XIX español y una ruptura con el constitucionalismo español anterior ${ }^{63}$. Si bien amplió los derechos consignados en la Constitución progresista española de 1869, su modelo de inspiración se encontró en las recientes constituciones alemana (1919), austriaca (1920) y checoslovaca (1920). Así lo atestiguan las múltiples referencias a estas constituciones durante el debate constitucional y la propia formación jurídica de los diputados constituyentes encargados de la redacción tanto del anteproyecto como del proyecto de Constitución.

El Estado institucional se impuso entre los constituyentes reformistas como una idea superadora del Estado-Poder. El carácter coactivo que hasta entonces había caracterizado la descripción del Estado esbozada por el constitucionalismo de finales del siglo XIX y principios del siglo XX daba paso a una concepción garantista del Estado. No obstante, la verdadera inspiración histórica del nuevo Estado republicano debe buscarse en el Derecho Público de procedencia austriaca y germana, que influyó decisivamente en los constituyentes redactores del anteproyecto constitucional, especialmente en Adolfo Posada, Alfonso GarciaValdecasas, Ángel Ossorio y Gallardo, Manuel Martínez Pedroso y Javier Elola. De la contribución de Adolfo Posada destaca su oposición a concebir el Estado como un instrumento esencialmente coactivo. En sustitución de esta fórmula propone el Estado "para el Derecho". El Estado se postula así como un instrumento normativo inserto, y no independiente en ningún sentido, en el Derecho ${ }^{64}$.

62 “Las ideas y los hechos", Acción Española, 15.12.1931, p. 58.

63 Joaquín Varela Suanzes-Carpegna, "Estado", en Fernández Javier Fernández Sebastián y Juan Francisco Fuentes (dirs.) Diccionario politico y social del siglo XX español, Alianza, Madrid, 2008, p. 292.

${ }^{64}$ Adolfo Posada, La crisis del Estado y el Derecho Politico, C. Bermejo, Madrid, 1934, p. 246. 
La Constitución de 1931 adopta requisitos jurídicos y económicos que promueven el Estado social. El papel intervencionista del Estado en los asuntos económicos se concibe como "tuitivo de los derechos y libertades de las personas comenzando por la igualdad"65. Más aún, la Constitución republicana supuso una superación parcial del Estado liberal de Derecho que en gran medida respondía a nuevas demandas sociales en su mayoría procedentes del ámbito obrero sindical66. Esa construcción de lo que hoy denominamos el Estado social de Derecho fue el resultado de un proceso histórico que comenzó en Europa tras la Primera Guerra Mundial67. El debate constitucional de 1931 convirtió la disputa ideológica de esos dos modelos de Estado en su tema fundamental.

Coincidiendo con la proclamación de la República el panorama jurídico y político cambia por completo. Se incorporan como catedráticos personalidades como Nicolás Pérez Serrano, Francisco Ayala, Eduardo Llorens y José Medina Echavarría, entre otros muchos. Esta renovación de la universidad influyó en una nueva forma de concebir las instituciones jurídicas y politicas como el resultado "de la cultura y la voluntad humana". El método filosófico-histórico se sustituye por un modelo de jurista que antepone la técnica jurídica sobre otro tipo de consideraciones $^{68}$.

La primera parte de la investigación ha examinado el papel de las elecciones generales de 1931 en la composición de las Cortes Constituyentes, destacando la fragmentación parlamentaria como un elemento crucial para entender la dinámica de los debates constitucionales en el Parlamento. El papel de la oposición quedó en manos de partidos minoritarios como resultado de la amplia coalición de gobierno. Ese aspecto, junto con la regulación de los turnos de intervención recogidos en el Reglamento Provisional de las Cortes Constituyentes, determinó que el respaldo electoral obtenido por los partidos políticos representados en las Cortes no tuviese ninguna influencia en la disposición de los turnos de intervención a lo largo del debate constitucional.

La segunda parte ha prestado atención a los argumentos de estabilidad y consolidación del nuevo Estado republicano a través de las intervenciones parlamentarias. Las preocupaciones comunes a los distintos partidos políticos consistieron en la promoción de un Estado fuerte, es decir, de un Estado con poder de decisión a través de sus órganos institucionales, y la defensa de la Constitución como norma que garantizaba la extensión de los derechos. Los argumentos de los constituyentes reformistas hacian hincapié en la necesidad de consolidar el nuevo régimen republicano frente a posibles amenazas. El especial celo con respecto a la protección del Estado explicaba la importancia de la idea de Estado a lo largo de las distintas discusiones en las Cortes.

La tercera parte ha recuperado tres debates sobre el proyecto constitucional en las Cortes: la relación entre la Constitución, las Cortes y el Estado; el papel del

65 Clara Álvarez Alonso, op. cit., p. 334.

66 José Manuel Canales Aliende, La Administración de la Segunda República: la organización central del Estado, Instituto Nacional de la Administración Pública, Madrid, 1986, p. 40.

67 Elías Díaz, "Estado de Derecho", en Alfonso Ruiz Miguel y Elías Díaz, E. (eds.) Filosofía Politica II: Teoria del Estado, Trotta, Madrid, 1996, pp. 72-73.

68 Sebastián Martín, "Funciones del jurista y transformaciones del pensamiento jurídicopolítico español (1870-1945)”, Historia Constitucional, 12, 2011, pp. 163-164. 
Estado en la economía y la propiedad privada; y la distribución de las competencias entre el Estado y las regiones. De ellos se señalan dos aspectos que quedan destacados en las distintas sesiones del debate. Por una parte, el reconocimiento y la garantía de los derechos individuales con respecto a las facultades extensas reconocidas al Estado y sus órganos; por otra, la relación legal entre el Estado y la Constitución de 1931 bajo la fórmula de nuevo cuño de influencia centroeuropea.

La cuarta parte del trabajo ha descrito las características básicas de los dos conceptos de Estado enfrentados en el Parlamento. Un primer concepto, expuesto por los partidos en la coalición de gobierno, consistente en el reconocimiento de las competencias del Estado para ampliar los derechos reconocidos constitucionalmente, junto con las garantias jurídicas del funcionamiento del Estado a través del modelo integral. Un segundo concepto, defendido por la Minoría Popular Agraria y diputados independientes, estuvo ligado a la plena garantía de los derechos individuales consagrados constitucionalmente en el texto de 1876. Se posicionaba en contra de la extensión de las competencias del Estado en materia religiosa, educación y derechos de propiedad y optaba por limitar la autonomía regional a través de la Constitución.

Fecha de envío / Submission date: 23/02/2019

Fecha de aceptación / Acceptance date: 14/04/2019 